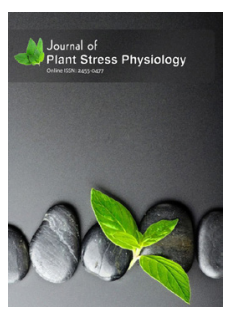

ISSN: $2455^{-0477}$

Received: March 27, 2019

Accepted: May 12, 2019

Published: May 14, 2019

*Corresponding Author:

Md. Rafiqul Islam

Email: rafiarib@yahoo.com

\section{Genetic variability of submergence tolerance in rice related to yield and yield contributing traits}

\author{
Md. Zahirul Islam', Md. Rafiqul Islam*, Md. Abdullah Al Mamun', \\ M Moynul Haque', Jalal Uddin Ahmed², Nurunnaher Akter', Md Abdul Karim' \\ 'Department of Agronomy, Bangabandhu Sheikh Mujibur Rahman Agricultural University, Gazipur-1706, \\ Bangladesh, 'Department of Crop Botany, Bangabandhu Sheikh Mujibur Rahman Agricultural University, \\ Gazipur-1706, Bangladesh
}

\begin{abstract}
Twenty-three rice genotypes were evaluated during kharif II season for understanding the submergence tolerance associated with short-duration and high yielding traits. For this, relative performance of seven quantitative plant traits of the genotypes viz. days to maturity, panicles per hill, panicle weight, spikelets sterility, spikelets per panicle, 1000 -seed weight and grain yield were analyzed under normal and submerged conditions. The genotypic variation was found in all the relative plant traits. Multivariate techniques viz. k-means cluster analysis and discriminant function analysis (DFA) were used for grouping the genotypes. Maximum number of genotypes (15) were grouped in cluster 3 followed by cluster 1 (4). The genotype BRRI dhan31, BRRI dhan39, BRRI dhan56 and BRRI dhan57 under cluster 1 performed better compared to other cluster members. DFA showed that function 1 and 2 explained 80.5 percent and 16.9 percent respectively with a cumulative of 97.4 percent of total variance of the genotypes. Panicles per hill, panicle weight, sterility percent, 1000-grain weight and grain yield mostly contributed in grouping the genotypes. The panicle weight followed by grain yield played the major role for the maximum variance in the genotypes. The results suggest that the short-duration genotypes BRRI dhan 33 and BRRI dhan 56 and BRRI dhan 57 performed better under submerged condition and the plant traits like panicle weight or grain yield could be the best choice for submergence tolerance in rice.
\end{abstract}

KEYWORDS: Genetic variability, submergence tolerance, yield traits, rice

\section{INTRODUCTION}

Rice is the staple food in many countries. In the Asian region, China, India, Indonesia, Bangladesh, Vietnam and Japan produce and consume more than 90 percent of the rice [1]. In Bangladesh, the growth rate of rice was 0.34 million ton (MT) per year during the periods from 2009-2010 to 2013-2014. Holding this trend, the country may able to produce a surplus of 2.6 MT of rice in 2050 with increased population [2]. However, many biotic and abiotic stresses can hamper achieving this target. On an average, flooding may affect about 25 percent of the total land every year but severe flood affect 60 percent of the land mass [3]. However, normal floods are considered a blessing for Bangladesh due to enriching soil fertility and availability of residual soil moisture after the monsoon [4]. From floods, the extent of damaging the crop varies depending on the duration of submergence, growth stage encountering submergence, varieties, and the prevailing weather conditions such as temperature, light and humidity. Prolonged flooding in Bangladesh provides the true deep water and floating rice environment where water depths may reach three meters or more and last for five to six months. In intermittent flooding, the rice crop may be suddenly submerged in 50 to $100 \mathrm{~cm}$ water, which completely drains off from the field in one or two weeks.

The research on developing submergence tolerance of rice is in progress. The main thrust of research is to develop aman rice varieties that can withstand submergence for up to two weeks or that can be planted after passing the high-risked flooding period [5]. The existing high-yielding aman rice varieties are normally suitable for the shallowly flooded area, but the variety is needed that can withstand deeply flooded areas inundated for a period of one or two weeks. It is important that aman rice varieties are unlikely to be made available for 32 percent area of the country that is flooded more deeply than $90 \mathrm{~cm}$. Bangladesh Rice Research Institute (BRRI) released two submergence-tolerant varieties namely BRRI dhan 51 and BRRI dhan 52 those were found to tolerate submergence for two weeks $[6,7]$. Another salt-tolerant variety BRRI dhan78 can survive for 14 days of complete submergence and released for the coastal regions of

Copyright: ๑ The authors. This article is open access and licensed under the terms of the Creative Commons Attribution License (http://creativecommons.org/licenses/by/4.0/) which permits unrestricted, use, distribution and reproduction in any medium, or format for any purpose, even commercially provided the work is properly cited. Attribution - You must give appropriate credit, provide a link to the license, and indicate if changes were made. 
Bangladesh [8]. Developing high yielding, short-duration and three to four weeks submergence tolerant rice variety is also in progress $[9,10]$.

The local cultivars available for cultivating in the aman season of Bangladesh are inherently submergence tolerant. It is recommended that for getting new submergence tolerant QTL, identified new submergence tolerant local cultivars can be used [11]. On the other hand, the present submergence tolerant varieties are long-duration and subjected to cold injury. Hence, short-duration submergence tolerant high yielding variety (s) are necessary especially under multiple flash-flood situations [6]. As a result, the information regarding the duration of submergence, sensitivity of growth stages to submergence and grain yield under submergence are needed to define clearly. Thus, an attempt is taken to conduct a systematic study involving other aman rice varieties including short-duration ones to improve rice productivity under flooding conditions. The specific objectives of the present study were to evaluate the submergence-induced changes in various phonological and yield traits of aman rice genotypes, and to identify the short-duration aman rice genotypes and desirable plant traits as selection criteria for submergence tolerance.

\section{MATERIALS AND METHODS}

\section{Location and Climate}

The study was conducted at the Field Laboratory of the Bangabandhu Sheikh Mujibur Rahman Agricultural University, Gazipur, Bangladesh from June to December 2014. The area is located in Madhupur Tract under 28 Agro-Ecological Zone at $24^{\circ} 05^{\prime}$ N latitude and $90^{\circ} 16^{\prime} \mathrm{E}$ longitude with an elevation of $8.4 \mathrm{~m}$ above the mean sea level. The land is a valley depression in a closely dissected terrace having silty clay soil. The area is characterized by subtropical climate having high rainfall during monsoon.

\section{Plant Materials}

A total 23 varieties of rice (Oryza saliva L.) including 16 improved varieties released by BRRI and 4 local transplanted aman varieties from different parts of Bangladesh and two shortduration variety BINA dhan 1 1, BINA dhan 12 from Bangladesh Institute of Nuclear Agriculture were used in the study (Table 1). A short-duration variety BU dhanl from Bangabandhu Sheikh Mujibur Rahman Agricultural University was also included. The seeds of all the genotypes were collected from trusted sources.

\section{Land Preparation}

The land preparation was done well by repeated plowing and cross plowing with a tractor-drawn disc plough and then harrowed. Each plowing was done followed by laddering for leveling the lands, collecting the stubbles and removing the weeds. The individual plots were made by making ridges (8-10 cm high) around each plot to restrict the loss of fertilizer with lateral runoff of irrigation water.

\section{Transplanting, Fertilization and Cultural Practices}

One month-aged seedlings were transplanted to the main field. Transplanting was done in the uniformly puddled field by maintaining $25 \times 15 \mathrm{~cm}$ spacing. Two seedlings per hill were transplanted. Fertilizers were applied as per recommendation for aman rice in AEZ 28 [12]. Triple super phosphate (TSP), gypsum and zinc sulphate and two-third muriate of potash (MOP) were applied during final land preparation. Urea was applied in two equal splits. First split of urea and one-third MOP were applied at 10 days after de-submergence (DAD) and second split urea were applied at 35 DAD. Sanitation was done at 7 days after subsiding of water. Weeding and other cultural practices including insect pest management were done whenever necessary.

\section{Imposition of Submergence Treatment}

The plants were submerged completely in the submergence tank to a depth of $70 \mathrm{~cm}$ above the soil surface. The water was made turbid twice daily by mixing the mud. This was done as much as possible to bring the similar situation occurred during actual flooding in nature. After 14 days of submergence, the tank was de-submerged. Complete submergence was done at 34 days after transplanting. During submergence, air and water temperature data were collected.

\section{Measurement of Water Turbidity}

Water turbidity was measured by turbidity meter (Lamotte 2020e Portable Turbidity Meter) during submergence. It was measured from different levels of water with the unit of nephelometric turbidity units (NTU). Water turbidity of submerged water at different dates and variable depth is illustrated in Figure 1. It increased with increasing water depth on 20 August and it ranged from 24 to 26 NTU. It might be because at early stages of submergence the particle just started sedimentation. The water turbidity was found to decrease thereafter as the particles are settled.

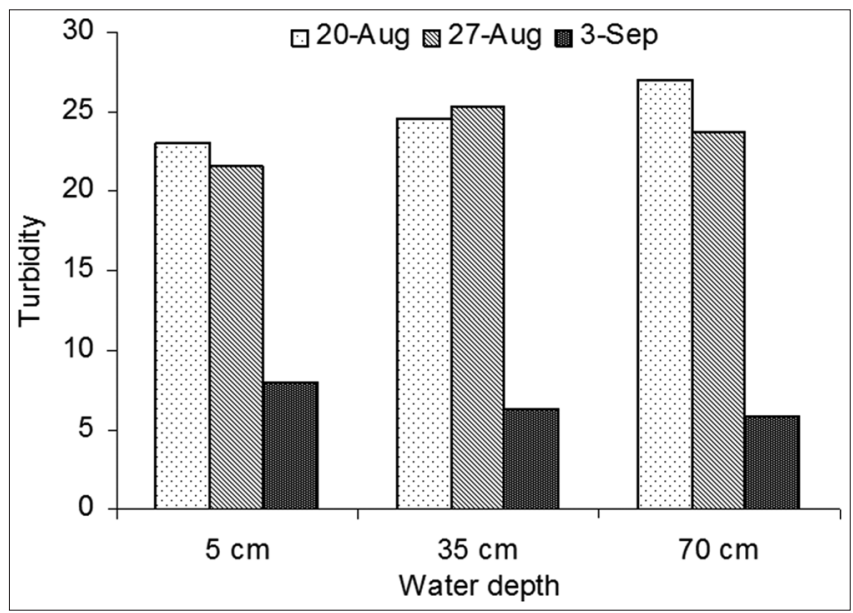

Figure 1: Change in turbidity of water at different depths during submergence 


\section{Measurement of Air and Water Temperature}

Two thermometers were used to take the maximum and minimum air and water temperature during submerged periods. For this, one was place below the water and another above the water surface. Daily average air and water temperature during submergence is illustrated in Figure 2. The average air temperature of the experimental plots varies from 29 to $35^{\circ} \mathrm{C}$. In contrast, the average water temperature lies between 27 and $30^{\circ} \mathrm{C}$. It means that water temperature remained comparatively lower than the air temperature during submergence.

\section{Tillering Dynamics and Crop Phenology}

The number of tillers of the selected four hills collected from each experimental plot was counted and finally the total number of tillers $\mathrm{m}^{-2}$ was calculated. The days required to turn color from greenish to brown at the base of the panicle of 50 percent tillers were designated as days to maturity.

Table 1: List of rice genotypes used in the experiment

\begin{tabular}{lll}
\hline SI. No. & Genotypes & Source \\
\hline 1 & BRRI dhan57 & BRRI \\
2 & BRRI dhan56 & BRRI \\
3 & BRRI dhan33 & BRRI \\
4 & BRRI dhan39 & BRRI \\
5 & BRRI dhan51 & BRRI \\
6 & BU dhan1 & BSMRAU \\
7 & BINA dhan11 & BINA \\
8 & BRRI dhan44 & BRRI \\
9 & Malshera & KURIGRAM \\
10 & BRRI dhan23 & BRRI \\
11 & BRRI dhan31 & BRRI \\
12 & BRRI dhan37 & BRRI \\
13 & Jol depa & KURIGRAM \\
14 & BRRI dhan40 & BRRI \\
15 & BRRI dhan49 & BRRI \\
16 & BRRI dhan22 & BRRI \\
17 & Shanjia & KURIGRAM \\
18 & BRRI dhan41 & BRRI \\
19 & BRRI dhan52 & BRRI \\
20 & BRRI dhan62 & BRRI \\
21 & BRRI dhan54 & BRRI \\
22 & Guti swarna & KURIGRAM \\
23 & BINA dhan12 & BINA \\
\hline
\end{tabular}

\section{Post-harvest Data Collection}

The plants were harvested at variable dates when attained full maturity. After harvesting, the spikelets were separated from panicles and the number of filled and unfilled grains per panicle was counted by a Multi Auto Counter (Model DCI NO: 501102 , Tokyo, Japan). Then 1000-grains were counted randomly from the filled-grain and weighed in an electronic balance (AND counting, FX-300). Grain yield was recorded from the middle of the experimental plots. After threshing and cleaning, the weight of the grains was recorded for each genotype and adjusted at 14 percent moisture content.

\section{Statistical Analysis}

Pearson correlation coefficients were used to estimate the direction and degree of linear association between plant traits as advocated by many authors [13-15]. Various multivariate techniques were used for grouping and identifying the genotypes tolerant to flooding with desirable traits [16]. In the study, seven qualitative variables were used in k-means cluster analysis and discriminant function analysis (DFA). Non-hierarchical k-means cluster analysis was performed to classify the genotypes into different clusters. Thus formed each cluster is having similar characteristics based on variables considered in the analysis. DFA was used for conformity of the results on grouping the genotypes. DFA nicely indicate whether a particular set of variables is useful in separating in previously defined groups. It also plays a vital role in identifying the set of variables contributed more in clustering a large number of genotypes into homogeneous groups.

\section{RESULTS AND DISCUSSION}

\section{Quantitative Plant Traits}

Different quantitative plant characters i.e. days to maturity, panicle per hill, panicle weight, sterility, spikelet per panicle and grain yield were studied in relative values (values of submergence relative to control) for proper understanding of the submergence tolerance in rice (Table 2). It reveals that almost all traits showed a wide range of variation. The genotypic variations under differential stresses were also observed in many studies [17-19].

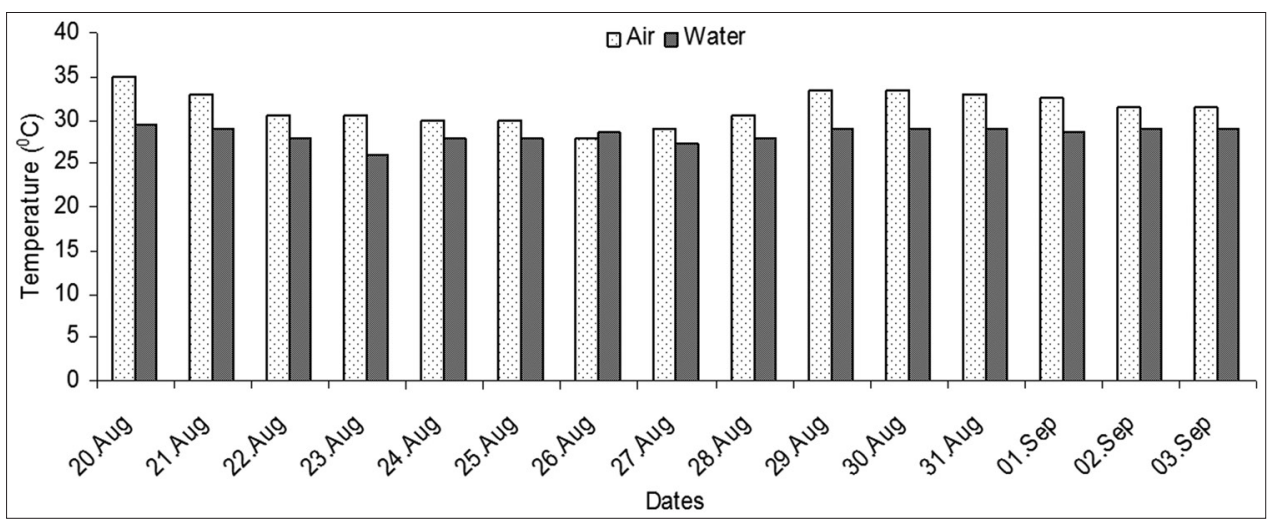

Figure 2: Changes in average air and water temperature in submerged plots during submergence 
The relative days to maturity of the genotypes were found in a range between 1.01 and 1.06 with an average of 1.03 . It means that some varieties needed more days to mature in submerged conditions. The relative number of panicles per hill ranged between 0.65 and 0.85 with a mean of 0.73 . Sixteen genotypes produced the relative number of panicle per hill below 0.75 but one genotype showed the relative number of tiller per hill greater than 0.85 . The relative panicle weight ranged between 0.51 and 1.01 with a mean of 0.75 . The lowest relative sterility percentage was found around 1.13 that rose to 1.47 with a mean of 1.27 . This indicates that submergence of rice produced numerous sterile spikelets. The higher positive skewness $(\alpha=0.87)$ indicates most of the genotypes are concentrated towards left of the distribution curve and less than median. However, eight genotypes were found to produce heavier sterile spikelets having more than 1.30 relative values. The relative spikelets per panicle ranged between 0.63 and 0.84 with a mean of 0.72 . Out of 23 genotypes, 4 were having the relative values greater than 0.75 and their performance was better. The relative grain weight was found around 0.96 that rose to 1.13 with a mean of 1.04 . This indicates that submergence of rice may increase grain weight to some extent. It reveals that 12 genotypes produced heavier grains under submergence showing relative values more than 1.00. Grain yield of the genotypes ranged between 0.47 and 0.75 with a mean of 0.61 . Three genotypes performed better showing the relative values in grain yield around 0.70 .

\section{Correlation between Plant Traits}

The correlation coefficient between seven relative plant characters exhibited that out of 21 coefficient, only two were highly significant at P 0.01 and two were significant at P 0.05 (Table 3). Among the plant characters related to yield and yield attributes, the highly strongly and significant positive correlation corresponded to grain yield and spikelets per panicle $\left(\mathrm{r}=0.74^{* *}\right)$. The grain yield had also strong positive correlations with the panicle weight $\left(\mathrm{r}=0.5 \mathrm{l}^{*}\right)$ and positive significant relationship with panicle per hill $(\mathrm{r}=0.49 *)$. It showed that seed yield had direct relations with the number of tillers per plant, panicle length, number of unfilled grain per panicle and chlorophyll content [20]. Various plant traits are reported to be associated with submergence tolerance in rice and grain yield could be an important selection criterion for submergence tolerance [21, 22]. The panicle per hill presented a strong and significant positive correlation with panicle weight $\left(\mathrm{r}=0.54^{* * *}\right)$. Days to maturity had a negative fair relationship with grain yield. This indicates that longer the phenological event lower was the grain production. Seed weight had negative correlations with yield components, but positive relations with days to maturity and grain yield.

\section{Multivariate Analysis}

In this study, two multivariate techniques were used to make the statistically homogenous groups of the rice genotypes subjected to submergence. The analyses included k-means non-hierarchical cluster analysis and discriminant function analysis (DFA). Clustering technique is useful in grouping the genotypes subjected to abiotic stresses [23]. The plant traits used in those analyses were the relative days to maturity, relative panicles per hill, relative panicle weight, relative spikelet sterility, relative spikelets per panicle, relative 1000-seed weight and relative grain yield.

\section{K-means cluster analysis}

Since there were considerable variations in almost all the quantitative relative plant characters, the genotypes were grouped into four clusters using k-means cluster analysis. The genotypes under each cluster can be considered highly similar. The maximum genotypes (15) belong to cluster 3 followed by cluster 1 (4), 2 (2), 4 (2). The cluster 1 is comprised of BRRI dhan31, BRRI dhan39, BRRI dhan56 and BRRI dhan57. They were characterized with the highest relative panicle weight $(0.921)$, spikelets per panicle $(0.777)$ and grain yield $(0.700)$ and were moderate panicle per hill (0.758), moderate sterility

Table 2: Variation in quantitative plant characters of 23 rice genotypes

\begin{tabular}{lclcc}
\hline $\begin{array}{l}\text { Variables in terms } \\
\text { of relative values }\end{array}$ & Range & $\begin{array}{l}\text { Mean } \pm \text { standard } \\
\text { deviation }\end{array}$ & $\begin{array}{c}\text { CV (percent) } \\
(\alpha)\end{array}$ \\
\hline Days to maturity & $1.01-1.06$ & $1.03 \pm 0.014$ & 1.32 & 0.07 \\
Panicles per hill & $0.65-0.85$ & $0.73 \pm 0.052$ & 7.05 & 0.58 \\
Panicle weight & $0.51-1.01$ & $0.75 \pm 0.111$ & 14.77 & 0.64 \\
Sterility percent & $1.13-1.47$ & $1.27 \pm 0.076$ & 5.95 & 0.87 \\
Spikelets per panicle & $0.63-0.84$ & $0.72 \pm 0.046$ & 6.31 & 0.73 \\
1000- seed weight & $0.96-1.13$ & $1.04 \pm 0.056$ & 5.38 & 0.35 \\
Yield & $0.47-0.75$ & $0.61 \pm 0.067$ & 10.91 & -0.52 \\
\hline
\end{tabular}

* The relative values are the ratio of the performance of each variable under submerged condition and control condition.

Table 3: Correlation coefficient of seven plant characters of 23 rice genotypes

\begin{tabular}{lccccccr}
\hline Parameters & DMAT & PPH & PW & STER & SPP & TSW & YI \\
\hline DMAT & 1.00 & & & & & & \\
PPH & 0.20 & 1.00 & & & & & \\
PW & -0.18 & $0.54^{* *}$ & 1.00 & & & & \\
STER & 0.16 & -0.02 & -0.12 & 1.00 & & & \\
SPP & -0.17 & 0.32 & 0.38 & 0.03 & 1.00 & & \\
TSW & 0.11 & -0.09 & -0.31 & -0.23 & -0.02 & 1.00 & \\
YI & -0.22 & $0.49 *$ & $0.51^{*}$ & -0.25 & $0.74 * *$ & 0.20 & 1.00 \\
\hline
\end{tabular}

*Correlation is significant at the 0.05 level (2-tailed).

**Correlation is significant at the 0.01 level (2-tailed).

DMAT-days to maturity, PPH-Panicles per hill, PW-Panicle weight,

STER-Sterility percent, SPP-Spikelets per panicle, TSW-1000-seed weight, YI-grain yield.

Table 4: Comparison profile of the four groups of rice genotypes classified by K-means clustering

\begin{tabular}{lcccc} 
Variables in terms of relative values $^{*}$ & \multicolumn{4}{c}{ Cluster } \\
\cline { 2 - 5 } & 1 & 2 & 3 & 4 \\
\hline Days to maturity & 1.031 & 1.051 & 1.039 & 1.045 \\
Panicles per hill & 0.758 & 0.781 & 0.723 & 0.662 \\
Panicle weight & 0.921 & 0.782 & 0.727 & 0.558 \\
Sterility percent & 1.263 & 1.406 & 1.244 & 1.352 \\
Spikelets per panicle & 0.777 & 0.743 & 0.713 & 0.669 \\
1000-grain weight & 0.991 & 0.999 & 1.064 & 1.001 \\
Grain yield & 0.700 & 0.621 & 0.613 & 0.486 \\
\hline
\end{tabular}

* The relative values are the ratio of the performance of each variable under submerged condition and control condition. 
percent (1.263) moderate days to maturity (1.031) and lowest 1000- grain weight (0.991). The cluster 2 contains genotypes BU dhan 1 and BRRI dhan 54 and mainly characterized by the highest relative panicle per hill (0.817), spikelet sterility (1.406) and days to maturity (1.051). The cluster 3 includes genotypes BRRI dhan22, BRRI dhan23, BRRI dhan33, BRRI dhan37, BRRI dhan40, BRRI dhan41, BRRI dhan44, BRRI dhan49, BRRI dhan51, BRRI dhan52, BRRI dhan62, Jol depa, Shanjia and Guti swarna and BINA dhan 12. These genotypes were characterized with the lowest spikelet sterility percent (1.244) the highest 1000-grain weight (1.064) but moderate performance for all other traits. Cluster 4 genotypes BINA dhan 11 and Malshera were mainly characterized by the lowest panicle per hill (0.662), panicle weight $(0.558)$ and spikelet per panicle $(0.669)$, grain yield $(0.487)$.

The clustering pattern of the genotypes revealed that the relative performance of the genotypes under cluster 1 was the best. Cluster 2 and 3 genotypes performed moderate and having similar characteristics including panicle weight, spikelet per panicle, Days to maturity and yield, but they were separated due to slight variation in grain weight and spikelet sterility. Finally, the cluster 4 genotypes performed poorly among all the clusters in respect of most of the plant characters.

\section{Discriminant function analysis}

The three discriminant functions that separated the clusters were obtained by the stepwise procedure. Eigenvalues and canonical correlation coefficient is illustrated in Table 5. Function 1 explained 80.5 percent and function 2 explained 16.9 percent, and altogether 97.4 percent of total variance. Table 5 also shows that the panicles per hill, panicle weight, spikelet sterility, 100-grain weight and grain yield mostly contributing in grouping 23 genotypes. These five characters mostly explained the total variance under function 1 and 2 . The coefficients of panicles weight and grain yield were higher in function 1 than that of in function 2. It means that these two plant characters contributed largely for the variance in function 1. On the other hand, the coefficient of panicles per hill and sterility percent was higher in function 2 indicating the contribution of this variable to function 2 . The almost similar coefficient values of grain weight in function 1 and 2 indicating this character equally contributed to both function 1 and 2 for the variation.

The coefficient of correlation between seven variables and three discriminatory functions is presented in Table 6. It reveals that panicle weight is placed at the top of the list of discriminatory variables with the correlation coefficient of 0.481 under function 1. It indicates that panicle weight played the most dominant role out of seven variables in explaining the maximum variance in 23 genotypes by stepwise DFA. Grain yield was the secondary important variables in explaining the variation in function 1. Spikelet sterility percent was also important in explaining the maximum variation under function 2. Venkatesan et al. [21] reported that the number of panicles per plant and grain weight contributed to the genetic divergence of rice under submergence and highly correlated with grain yield.
Table 5: Eigen values and latent vectors accompanying with the first three discriminant functions

\begin{tabular}{lccc} 
& \multicolumn{3}{c}{ Discriminant functions } \\
\cline { 2 - 4 } & $1^{\text {st }}$ & $2^{\text {nd }}$ & $3^{\text {rd }}$ \\
\hline Extracted Eigen values & 12.10 & 2.54 & 0.40 \\
Percentage variance & 80.5 & 16.9 & 2.6 \\
& \multicolumn{3}{c}{ Eigenvectors } \\
\hline Panicles per hill & -0.501 & 0.840 & 0.715 \\
Panicle weight & 1.138 & -0.298 & 0.015 \\
Sterility percent & -0.015 & 0.922 & -0.048 \\
1000-grain weight & -0.605 & -0.566 & 0.748 \\
Grain yield & 1.372 & 0.020 & -0.197 \\
\hline
\end{tabular}

Table 6: Correlations between seven discriminating variables and standardized canonical discriminant functions of 23 rice genotypes

\begin{tabular}{lccc}
\hline Discriminating variables & \multicolumn{3}{c}{ Discriminant Function } \\
\cline { 2 - 4 } & 1 & 2 & 3 \\
\hline Panicle weight & $0.481^{*}$ & 0.078 & 0.174 \\
Sterility percent & -0.066 & $0.585^{*}$ & -0.221 \\
Panicles per hill & 0.175 & 0.359 & $0.767^{*}$ \\
Thousand grain weight & -0.088 & -0.326 & $0.703^{*}$ \\
Grain yield & 0.354 & -0.071 & $0.444^{*}$ \\
Days to maturity & -0.151 & 0.092 & $0.301^{*}$ \\
Spikelets per panicle & 0.053 & 0.000 & $0.070^{*}$ \\
\hline
\end{tabular}

Variables ordered by absolute size of correlation within function.

* Largest absolute correlation between each variable and any discriminant function

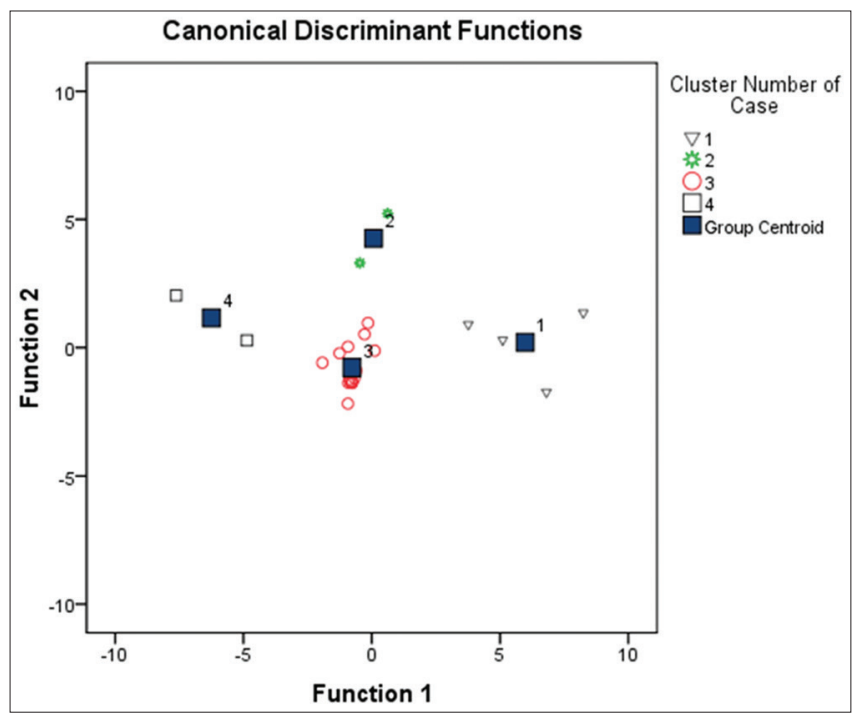

Figure 3: Graphic illustration of the discriminatory analysis of four groups of rice genotypes

Figure 3 illustrates how the genotypes are classified into four clusters according to the first two discriminatory functions. The function 1 clearly separated cluster 4 from cluster 1 . Genotypes situated at the right side of the diagram (cluster 1) are higher panicle weight and produced more grain yield under submerged conditions and those of the left side (cluster 4) produced lower in respect of these two characters based on $\mathrm{X}$ ordinate. The genotypes under others clusters were intermediate in producing 
Table 7: Major relative plant characters of four accessions mostly representing their respective clusters

\begin{tabular}{lllllllll}
\hline $\begin{array}{l}\text { Cluster } \\
\text { No. }\end{array}$ & Genotypes & DMAT & PPH & PW & STER & SPP & TGW & Yi \\
\hline 1 & BRRI dhan57 & 1.05 & 0.74 & 0.77 & 1.24 & 0.85 & 0.99 & 0.76 \\
2 & BU dhan1 & 1.03 & 0.82 & 0.76 & 1.34 & 0.76 & 1.00 & 0.61 \\
3 & BRRI dhan33 & 1.05 & 0.65 & 0.79 & 1.27 & 0.64 & 1.00 & 0.51 \\
4 & BINA dhan 11 & 1.04 & 0.66 & 0.61 & 1.31 & 0.64 & 1.00 & 0.50 \\
\hline
\end{tabular}

$\mathrm{DMAT}=$ Days to maturity, $\mathrm{PPH}=$ Panicles per hill, $\mathrm{PW}=$ Panicle weight, STER $=$ Sterility percent, $T G W=1000$ - grain weight, $Y i=$ Grain yield.

yield. On the other hand, the genotypes on the upper side of the diagram (cluster 2) produced higher panicles per hill and having higher spikelet sterility compared to the genotypes scattered at the bottom of the diagram (cluster 3). Therefore, Function 2 separated cluster 2 from cluster 3 based on Y ordinate.

\section{Representative genotypes}

Figure 3 showed the orientation of genotypes under each of four clusters. The relative position of the genotypes is based on the cumulative responses of the variables representing the function 1. Group centroid of each cluster represented the optimum values of function 1 and function 2 that has resulted from the cumulative effects of all genotypes in the response of discriminating variables. The genotype very closed to the group centroid might be considered as the most representative (might not the best) of that cluster. Accordingly, the genotype BRRI dhan 57 in cluster 1 , genotype BU dhanl in cluster 2 , the genotype BRRI dhan 33 in cluster 3 and the genotype BINA dhan 11 in cluster 4 might be considered as more representative of their respective clusters (Table 7).

\section{CONCLUSIONS}

The results reveal that the rice genotypes showed a wide range of variation in growth duration, yield and yield traits under submerged conditions. Among the seven quantitative plant traits, panicle weight or grain yield could be the best plant trait as selection criteria for submergence tolerance in rice genotypes. Some short-duration like BRRI dhan 33 and BRRI dhan 56 are having better-tillering dynamics under submerged condition and could be used in flood-prone areas in Bangladesh. However, further study is essential for affirmation of the results and study directing to molecular approach is suggested.

\section{REFERENCES}

1. Abdullah A, Kobayashi H, Matsumura I, Ito S. World Rice Demand Towards 2015: Impact of Decreasing Demand of Per Capita Rice Consumption for China and India. Asmadi Hassan, A, Nasrudin M, Akhir M (eds), Japan and East Asian Regionalism, Kuala Lumpur: East Asian Studies Department, 2008

2. Kabir MS, Salam MU, Chowdhury A, Rahman NMF, Iftekharuddaula KM, Rahman MS, Rashid MH, Dipti SS, Islam A, Latif MA, Islam AKMS, Hossain MM, Nessa B, Ansari TH, Ali MA and Biswas JK. 2015. Rice
Vision for Bangladesh: 2050 and Beyond. Bangladesh Rice Journal. 2015; $19(2): 1-18$

3. World Bank. Bangladesh Disaster Risk and Climate Resilience Program, July 15, 2018. https://www.worldbank.org/en/country/ bangladesh/brief/bangladesh-disaster-risk-climate-change-program

4. Rahman MR. Impact of riverbank erosion hazard in the Jamuna Floodplain areas in Bangladesh. Journal of Science Foundation. 2010; 8 (1\&2): 55-65.

5. Asaduzzaman M. Getting Agriculture Moving Once Again: Strategic Options for Post-HYV Agriculture in Bangladesh. (UK) Department for International Development (DFID), Dhaka. 2009.

6. Iftekharuddaula KM, Ahmed HU, Ghosal S, Moni Z, Amin A, Ali MS. Development of new submergence tolerant rice variety for Bangladesh using marker-assisted backcrossing. Rice Science. 2015; 22 (1): 16-26

7. Malabayabas M, Yamano T, Noor T. Adoption of submergence-tolerant rice varieties BRRI dhan51 and BRRI dhan52 in northern Bangladesh. STRASA Economic Brief, IRRI Bill and Melinda Gates Foundation. October 2014.

8. BRRI (Bangladesh Rice Research Institute). BRRI Annual Report 2016-2017 Bangladesh Rice Research Institute, Gazipur, 2017.

9. Ray BP. Genetic analysis and development of submergence tolerance rice (Oryza sativa I.) lines through MAS. International Journal of Complement Alternative Medicine. 2018; 11(4): 244-249.

10. Islam MR, Anisuzzaman M, Aditya TL, Iftekharuddaula KM Advancement in rice varietal development to sustain food security in Bangladesh. Eco-friendly Agricultural Journal. 2014; 7(10): 127-136.

11. Al Amin, Iftekharuddaula KM, Sarker A, Talukder AH, Ghoshal S, Shalahuddin AKM, Tamal Aditya TL, Ali MA, Collard B. Identification of Novel Submergence Tolerant Local Rice Cultivars of Bangladesh. International Journal of Genetics and Genomics 2018; 6(4): 44-51.

12. FRG. Fertilizer Recommendadion Guide, Bangladesh Agricultural Research Council (BARC), Farmgate, Dhaka 1215. 2012; 274p.

13. Abdala AJ, Bokosi JM, Mwangwela AM, Mzengeza TR. Correlation and path co-efficient analysis for grain quality traits in $\mathrm{F} 1$ generation of rice (Oryza sativa L.). Journal of Plant Breeding and Crop Science. 2016; 8:109-116.

14. Mohammadi R, Farshadfar E, Amri A. Path analysis of genotype $x$ environment interactions in rainfed durum wheat. Plant Production Science. 2016; 19:43-50.

15. Clifford, HT, Stephenson W. An introduction to numerical classification. Academic, London 1975

16. Islam MR, Hamid A, Khaliq QA, Ahmed JU, Haque MM Karim MA Genetic variability in flooding tolerance of mungbean (Vigna radiata $\mathrm{L}$. Wilczek) genotypes. Euphytica. 2007; 156 (1\&2): 247-255.

17. Haque, KMS, Karim MA, Bari MN, Islam MR. Genotypic variation in the effect of drought stress on phenology, morphology and yield of aus rice. International Journal of Biosciences. 2016; 8: 73-82.

18. Sarkar RK, Bhattacharjee B. Rice genotypes with Sub 1 QTL differ in submergence tolerance, elongation ability during submergence and re-generation growth at re-emergence. Rice. 2011; 5:7.

19. Panda D, Rao DN, Sharma SG, Strasser RJ, Sarkar RK. Submergence effects on rice genotypes during seedling stage: Probing of submergence driven changes of photosystem 2 by chlorophyll a fluorescence induction O-J-I-P transients Photosynthetica. 2006; 44 (1): 69-75.

20. Afrin W, Hossain MA, Islam MM. Evaluation of yield and yield contributing traits for submergence tolerance of rice. Progressive Agriculture. 2017; 28 (1): 7-11.

21. Venkatesan M, Sowmiya CA, Anbarasi B. Studies on genetic diversity of rice (Oryza sativa) under submergence. Plant Archives. 2018; 16 (2): $617-620$

22. Vergara GV, Nugraha Y, Esguerra MQ, Mackill DJ, Ismail AM. Variation in tolerance of rice to long-term stagnant flooding that submerges most of the shoot will aid in breeding tolerant cultivars. AoB PLANTS. 2014; 6: plu055

23. Reddy BS, Rani MG. 2018. Molecular and morphological characterization of near isogenic lines developed for major abiotic stresses of rice (Oryza sativa L.). International Journal of Current Microbiology and Applied Sciences. 2018; 7 (1): 2782-2797. 